\title{
Remote Sensing Applications: Beyond Land-Use and Land-Cover Change
}

\author{
Chris W. Baynard \\ Department of Economics and Geography, University of North Florida, Jacksonville, USA \\ Email: cbaynard@unf.edu, cbaynard@gmail.com
}

Received June 28, 2013; revised July 28, 2013; accepted August 8, 2013

Copyright (C) 2013 Chris W. Baynard. This is an open access article distributed under the Creative Commons Attribution License, which permits unrestricted use, distribution, and reproduction in any medium, provided the original work is properly cited.

\begin{abstract}
Remotely sensed (RS) imagery is increasingly being adopted in investigations and applications outside of traditional land-use land-cover change (LUCC) studies. This is due to the increased awareness by governments, NGOs and Industry that earth observation data provide important and useful spatial and temporal information that can be used to make better decisions, design policies and address problems that range in scale from local to global. Additionally, citizens are increasingly adopting spatial analysis into their work as they utilize a suite of readily available geospatial tools. This paper examines some of the ways remotely sensed images and derived maps are being extended beyond LUCC to areas such as fire modeling, coastal and marine applications, infrastructure and urbanization, archeology, and to ecological, or infrastructure footprint analysis. Given the interdisciplinary approach of such work, this paper organizes selected studies into broad categories identified above. Findings demonstrate that RS data and technologies are being widely used in many fields, ranging from fishing to war fighting. As technology improves, costs go down, quality increases and data become increasingly available, greater numbers of organizations and local citizens will be using RS in important everyday applications.
\end{abstract}

Keywords: Remote Sensing Applications; Mapping; Monitoring; Detection; Earth Observation

\section{Introduction}

A review of the literature regarding the application of remote sensing (RS) data and techniques to solve problems, address policy implications and improve decision making indicates a strong preference for studies focused on land use and land cover change (LULCC). This is not surprising given that earth observation (EO) data provide important and useful spatial and temporal information for studying changes in the natural environment; particularly those caused or affected by human actions, as well as for understanding what these changes are doing to us. As this awareness grows, governments, the public and industry are becoming responsive to the importance of ecosystem goods and services and the monetary value that must necessarily be placed on them $[1,2]$.

For example, new programs are being developed, known as payments for ecosystem services (PES) to conserve natural areas, mostly in developing countries [3]. One such program is known as REDD ${ }^{1}$ - reducing

${ }^{1}$ In December 2010, Google Labs released Google Earth Engine, a project that uses 25 years of Landsat TM and ETM+ data to enable global change monitoring. A primary aim is for developing nations to monitor their forests and to serve projects such as REDD (Landsat News, 2010). greenhouse gas emissions from deforestation and degradation. It draws on financial resources from developed countries to halt deforestation in forest-rich developing countries $[4,5]$.

Toward this aim, advances in RS are improving understanding of social and ecological systems functioning [5], which can range from intact native ecosystems to highly modified ones [6]. A central approach for comprehending dynamic landscapes is to recognize that vegetation is a driving force in terrestrial ecosystems and is often used as a proxy for classification [6]. This is noteworthy, since the type of vegetation growing in a given region provides an indication of climate (namely temperature and rainfall) and thus the type of socioeconomic activities that are likely to be found there. Furthermore, LULCs influence climate change.

Categorizing and examining landscapes, therefore, is a common topic in much of the LUCC literature. Here, remote sensing data are regularly utilized to assess spatial and temporal dynamics usually within a geographic information system (GIS) that is then used to analyze and map these patterns [7]. While much work focuses on using discrete classifications, whereby given land uses 
and land covers are placed into distinct categories, others prefer to use continuous data. The latter acknowledges that real landscapes do not abruptly end or sharply transit from one type to another. Using continuous data, such as vegetation indexes (e.g. Normalized Difference Vegetation Index, or NDVI), provides a more accurate representation of real world transitions between different landscape categories [8-10].

Consequently, a central focus on LUCC has been on deforestation, namely via agriculture, and logging, since these are direct drivers of landscape change. However, secondary, distal, or underlying drivers leading to such changes have socioeconomic, cultural, political and environmental explanations that vary by scale [11-14] and are harder to discern, since a RS image can show what is happening but not necessarily why.

The use of remote sensing images and derived maps is to better understand distal (secondary) drivers of change, as well their use beyond LUCC leads to multidisciplinary work that includes:

- Monitoring urban expansion, urban sprawl, slums and heat island effects through the use of daytime and nighttime imagery, as well as ground temperature and urban vegetation [15-25].

- Global fisheries management [26], including night time squid fishing efforts in the Pacific [27], increaseing fishing efficiency while reducing costs [28], improving aquaculture, such as shrimp farms [29]; tracking lobster movements [30]; detecting chlorophyll concentrations in the ocean and estimating phytoplankton mass and prey availability [28,31,32]; improving algorithms for classifying and monitoring algal blooms [33,34] and detecting and mapping broad scale coral reef changes [35].

- Modeling wildland fires and gauging potential damage from coal seam fires and detecting burn scars [36-38].

- Producing high-quality bathymetric maps [39].

- Monitoring drinking water quality, turbidity and water quality in coastal and estuarine waters [40-41]; improving efficiency of hydroelectric reservoirs and assessing cumulative environmental alterations resulting from new dams $[42,43]$.

- Detecting thermal plume discharges from nuclear power stations [44].

- Monitoring and mapping salinity distributions in coastal environments [45]; identifying coastline changes and associated impacts [46] and improving edge detection in ocean color images [47]. Also, detecting sea ice for arctic monitoring [48] and forecasting glacier melting [18,49].

- Improving accuracy in archaeological work, detecting buried objects and identifying potential historic sites. Monitoring the evolution of mining induced subsi- dence [50-56].

- Studying historic debris flows and identifying potential ones at stratovolcanoes [57].

- Identifying villages and urban areas at high-risk of malaria transmission and tracking mosquito habitats [58-61]; modeling seasonal and inter-annual patterns of climatic suitability for mosquitoes [62] and guiding aid efforts to areas with severed communications such as those following a major earthquake or cyclone [63-66].

- Modeling the impacts of a liquefied natural gas tanker explosion [67].

- Detecting infrastructure alterations related to oil exploration and production activities [68-72]; deforestation and soil contamination $[73,74]$.

- Military operations such as pre-mission planning and post-mission analysis, providing situational awareness for warfighters, developing threat analysis and identifying terrorist hideouts [75,76]; and netcentric warfare, which allows "warfighters to plan, execute, report and visualize a common operating picture" [77].

Given the broad nature of such research, data derived from remote sensing technologies are necessarily complemented with additional or ancillary data. This includes in situ measures; information about ecosystem goods and services; elevation, air and water temperature; rainfall data; hydropower potential; salinity; risk for erosion; the amount of carbon storage; displacement of local communities; habitat fragmentation and loss of wildlife; downstream and drinking water quality and quantity; wind speed; chlorophyll-a concentrations; agricultural production and the impact on food security; and health effects among others.

Having addressed the commonalities that exist in the LUCC literature, this review paper provides an insight into how RS-derived data are being used beyond traditional LUCC maps and images to better understand human-environment interactions, solve problems and address policy issues. Nevertheless, it is impossible to decouple the natural and cultural (human made) landscape from these studies since humans live and operate in particular locations whose specific qualities and histories provide a suite of possibilities to which inhabitants adapt in a variety of ways. This underscores the importance of understanding and implementing geographic thought and spatial analysis.

Thus, while traditional LUCC studies might focus on how humans interact with and transform the landscape, understanding why, and what are some of the socioeconomic effects, which takes us to the secondary drivers. Not surprisingly, given the multidisciplinary nature of this type of the research, a review of this literature indicates that the work being done does not necessarily fall 
into clean categories such as economics or health or risk assessment. Many of these issues are intertwined. For example, floods in Bangladesh have environmental components (monsoon rains) that are exacerbated by lack of planning, population growth, lack of funding for proper infrastructure, non-enforcement of construction/settlement policies in high-risk areas, bureaucracy in terms of several and often overlapping agencies, land speculation, and loss of arable land among others [7].

This paper, therefore, groups work that is similar into the following categories: Fire Models and Methods; Coastal and Marine Applications; Infrastructure and Urbanization; Archaeology and Remote Sensing; The Ecological Footprint, or the Landscape Infrastructure Footprint, and Ecosystem Goods and Services. These sections also address the types of ancillary data used in these research papers as well as the type of RS data involved and relevant characteristics (when provided). The Conclusion and Future Research sections follow. Given the breadth of this topic, this review provides a general introduction to the following topics and is not exhaustive. Readers are directed to the numerous references at the end of the paper, as well as the future research section, that identifies 13 well-known RS journals.

\section{Review}

\subsection{Fire Models and Methods}

Wildland fires pose a major environmental problem for many of the planet's ecosystems and can become an important cause of land degradation and environmental transformation [36-38]. Furthermore they pose a substantial economic risk in terms of lost forested land, loss of soil nutrients which can affect agricultural production [78], affected homes and property, as well as a health risk to nearby populations and a danger to fire fighters. One way to develop management scenarios for wildland fires involves using RS to detect the spatial distribution of fuel types in order to create more robust fire models [37].

Aerial photo interpretation is widely used by forest managers and government agencies, because it provides a compromise between price and precision, and is therefore "one of the most commonly used techniques for mapping vegetation and fuel types" [37]. These authors note that satellites are also being used to study forest fuels, but a main drawback is their inability to penetrate forest canopies. Nevertheless, using QuickBird imagery, some researchers have reported fuel map accuracies of $75 \%$ to $81 \%$ [37].

Investigators, such as Chuvieco et al. [36] also consider moisture status of vegetation, ignition sources and stakeholder values in their work. Using mainly Landsat
TM images, the authors were able to map and classify fire scars over time in the Cape Canaveral National Seashore in Florida using the categories burned and unburned. The objective was to establish sound management practices that balanced managed with natural fire regimes.

Duncan et al. [79] note that remote sensing techniques can prove suitable for fire monitoring as well. For example, for recent fire history at coarse scales, they suggest using MODIS Fire (Moderate Resolution Imaging Spectroradiometer) (see $[80,81]$ ), TRMM VIRS (Tropical Rainfall Measuring Mission, Visible and Infrared Scanner- $4.4 \mathrm{~km}^{2}$ pixels) and ATSR-2 (Along-Track Scanning Radiometer-1 km spatial resolution) [79,82], though in their work they relied on LANDSAT TM (30 and $120 \mathrm{~m}$ ) [83] imagery to help detect burn scars, among other features. But "For longer fire histories, especially when fine detail pattern information is necessary, mapping fire scars from a time series of high resolution imagery is preferred," [79]. Smith et al. [80] concur on the need to use higher spatial resolution satellite imagery than that provided by Landsat ETM+ $(15,30$ and $60 \mathrm{~m})$ $[83,84]$. In particular they refer to the importance of identifying the white ash that remains after fires, which provides an indication of fire severity.

Coal seam fires create another important fire risk, particularly in China, where $70 \%$ of the country's energy is derived from coal and where an estimated $20 \mathrm{Mt}$ of uncontrolled fires burn there every year [85]. In such cases Voigt et al. [85] propose an integrated satellite remote sensing approach to detect and monitor "near surface coal seam fires by observing land surface changes induced by fires" that includes digital elevation models (DEMs), radar and MODIS (250, 500 and $1000 \mathrm{~m})$, QuickBird (0.50 cm to $2.4 \mathrm{~m})$, ASTER (15, 30 and $90 \mathrm{~m})$ (see [86]) and Landsat 7 ETM+ data $[84,85,87]$. The monetary costs associated with these fires stem from not only the loss of the burnt coal itself, but also from the loss of accessibility to nearby mining operations [85]. Furthermore, these uncontrolled coal fires lead to environmental stresses through the release of large amounts of toxic and greenhouse gases such as $\mathrm{CO}, \mathrm{CO}_{2}, \mathrm{CH}_{4}$, $\mathrm{SO}_{2}$, and $\mathrm{NO}[85]$.

Prakash et al. [88] used Landsat imagery to identify coals seam fires burning in Alaska based on summertime thermal infrared temperatures. Noting that many of these fires go unnoticed and unreported in inaccessible areas, the authors found that coal seam fire zones exhibited temperatures $5^{\circ} \mathrm{C}$ to $14^{\circ} \mathrm{C}$ higher than surrounding areas [88]. Using Landsat ETM+ imagery, the authors focused on band 6 (low-gain band 61), the thermal infrared band, which operates in the $10.4-12.5 \mu \mathrm{m}$ spectral region and has a spatial resolution of $60 \mathrm{~m}$. Thus, high-resolution imagery was not necessary for this approach. 


\subsection{Coastal and Marine Applications}

The SeaWIFS (Sea-viewing Wide Field-of-view Sensors) Project (see [31]) provides quantitative data on bio-optical properties (color) of the world's oceans, based on chlorophyll and other plant pigments, whose higher concentration make the water greener $[28,31]$. For example, high-resolution airborne data have been used to estimate chlorophyll-a concentrations in Alaskan coastal waters in reference to phytoplankton biomass and prey availability for the Steller sea lion [32]. For these types of studies the authors noted that satellite footprints had two main limitations: chlorophyll-a variations require scale detection less than $1 \mathrm{~km}$, and stray light from land and bottom radiance of shallow waters tend to contaminate near-shore pixels (Montes-Hugo et al., 2005).

Meanwhile, Zagaglia et al. [26] examined the relationship between tropical Atlantic yellowfin tuna and environmental variables obtained from remote sensors in support of global fisheries management and the capture of pelagic species. They examined sea surface temperatures using Advanced Very High Resolution Radiometer (AVHRR) data onboard NOAA satellites $(1.09 \mathrm{~km})$ $[89,90]$; concentration of chlorophyll-a using SeaWIFS data from the SeaStar satellite; sea surface height anomaly information gathered from TOPEX and Poseidon altimeters; and surface wind data collected by scatterometers aboard the European Remote Sensing Satellites ERS-1 and -2. The authors found that tuna catch was strongly associated with the position of the Intertropical Convergence Zone (ITCZ) [26].

In another study, Rajitha et al. [29] discussed how satellite RS technology and GIS were being used to sustainably manage shrimp aquaculture in India. Here, management is important due to mangroves, coastal and marine resources, and agricultural rice lands being used and converted to create shrimp farms. At the same time, shrimp farms create rural employment and economic development in coastal villages, contributing "a major portion of national income through high export earning" [29]. Studies examined by the above authors note the effective use of Indian Remote Sensing Satellites (IRS), with $5.8 \mathrm{~m}$ to $1 \mathrm{~km} \mathrm{~m}$ resolution [91], Landsat TM and ETM+ for observing biological productivity and for monitoring coastal water temperature and quality [29].

In an additional application of RS to fishing, Santos [28] noted how "satellite delivered fishery-aid charts can reduce $25 \%$ - $50 \%$ of US commercial fisheries search time," greatly decreasing fuel consumption and the associated $\mathrm{CO}_{2}$ emissions, as well as improving fishing efficiency and increasing economic returns. Important data for the rational management of fishing resources includes water temperature and phytoplankton biomass, which the Coastal Zone Color Scanner (CZCS) provided until 1986, followed by the SeaWiFS sensors [28]. Active systems such as Light Detection and Ranging (LIDAR) and Side-Looking Airborne Radar (SLAR) to determine the location and size of fish schools, as well as microwave sensors aboard satellites such as SEASAT to map kelp resources along the California coast have also been implemented [28].

Waluda et al. [27] used satellite-derived imagery for another fishing study, albeit through a different perspective. These researchers utilized DMSP-OLS [39] to quantify squid fishing in the eastern Pacific based on lights. Since commercial fishery of Jumbo flying squid is conducted at night using powerful lights to attract these creatures, Waluda et al. [27] were able to quantify fishing effort based on light signatures of these vessels. "The distribution of lights can be used to observe the distribution and abundance of squid jiggers, and by inference, the distribution of exploited squid stocks, and the location of favorite fishing grounds" [27].

Producing high quality bathymetric maps requires expert personnel and expensive field surveys and high tech equipment, note Ceyhun and Yalçin [39], who found that Aster and QuickBird imagery could be successfully used to reduce the cost and labor needed to produce bathymetric measurements. In situations where detailed mapping was not necessary, Aster images worked fine, noted the authors, but for detecting local depth changes, QuickBird imagery was superior. Yuan and Zhang [92] also used QuickBird images to map and monitor the distribution and growth of submerged aquatic vegetation on a large scale.

Regarding rock lobster fisheries in Tasmania, Lucieer and Pederson [30] processed bathymetric data to derive a digital terrain model (DTM) to help track lobster movement. By then applying landscape classifications (developed by terrestrial ecologists) they quantified the degree and spatial distribution of habitat complexity. They accomplished this by classifying each grid in a bathymetric digital elevation model (DEM) into one of six predetermined morphometric landform classes. This provided more complex seabed characterizations that in turn helped quantitatively predict consequences of different management strategies [30].

RS has proven effective as a tool for detecting and mapping broad scale coral reef changes too [35]. By using pan-sharpening methods on FORMOSAT-2 imagery, the authors transformed $8 \mathrm{~m}$ spatial resolution images into higher resolution ones, noting a cost savings over purchasing high spatial resolution images alone. The methods involve using the panchromatic (black and white) band with its higher spatial resolution of $2 \mathrm{~m}$, and resampling the other (lower resolution) bands to produce a composite $[35,93]$. The estimated brightness values of the lower resolution bands are replaced with the higher panchromatic band and this is possible because the latter 
covers the same spectral range as the visible (red, green, blue) and near infrared bands [35].

Monitoring, predicting and understanding the availability of water and associated changes in quality entails work by Chang et al. [40], who examine satellite imagery to assess water availability and quantify the hydrological cycle. The authors used GOES (Geostationary Operational Environmental Satellites) [93], Landsat and MODIS data, ground level radar-precipitation data (NEXRAD), as well as past point measurements (changes in water quality at specific locations, river discharge and precipitation), to create a metropolitan water availability index (MWAI) for Tampa, Florida.

Also regarding water availability, Alcântara et al. [42] utilized MODIS data to conduct time and cost effective water quality measures in a Brazilian hydroelectric reservoir (Itumbiara). Using 786 daytime and 473 nighttime images, the researchers computed descriptive statistics (mean, maximum and minimum) to build a time series of day and night monthly mean temperatures used to better understand spatial and temporal variations in the tropical reservoir.

Focusing on the Pearl River Estuary in southern China, Chen et al. [41] used RS data as a tool for ecosystem restoration by focusing on turbidity, defined as an "optical effect that is related to the concentration of total suspended solids (TSS) and the shape and size of other impure elements in water" [41]. The researchers recommend using EO-1 ALI satellite imagery (Earth Observing, Advanced Land Imager-10 and $30 \mathrm{~m}$ ) [94] for water quality measurements in coastal and estuarine waters.

Li and Damen [46] note that the Pearl River delta "has one of the highest economic development rates of China" leading to loss of agricultural land, sea water intrusion, land subsidence, river siltation and coastal erosion. Combining data from Landsat (MSS, TM and ETM+) (see [95]) and SPOT imagery (see [96]) with topographical and nautical data helped $\mathrm{Li}$ and Damen [46] identify coastline changes and related impacts such as the narrowing of river channels, severe flooding, and increased sedimentation, which hinder harbor construction.

AVHRR data was used to detect the thermal plume created by the discharge of warm water from the Daya Bay Nuclear Power Station's cooling system into Daya Bay, China [44]. With a $1.1 \times 1.1 \mathrm{~km}$ resolution, the authors found that the thermal plumes displayed a seasonal pattern (smaller in winter and larger in summer) and that the temperature difference ranged from $1.0^{\circ}$ to $1.5^{\circ}$ from non-plume areas.

RS data is also being used to detect sea ice in an effort to monitor arctic conditions. In some cases low-resolution data, $25 \times 25 \mathrm{~km}$, is being used to examine sea ice extent and develop regression equations for spring and summer seasons [48]. In this study, Drobot [48] refers to data gathered from the Scanning Multichannel Microwave Radiometer (SMMR), the Special Sensor Microwave/Imager (SSM/I) and AVHRR Polar Pathfinder.

Finally, Wang and $\mathrm{Xu}$ [45] point out how RS techniques can be used to monitor salinity in coastal environments by using Landsat TM images to map salinity distribution in Lake Pontchartrain, Louisiana. They found that Landsat TM bands 1, 2, and 4 were positively correlated to salinity levels and that band 2 helped explain up to $20 \%$ of the variance. Meanwhile, bands 3 and 5 were negatively correlated to salinity levels and explained about $30 \%$ of the variance. The authors also found that hurricanes, such as Katrina, altered spatial patterns of salinity and significantly increased the average salinity levels.

\subsection{Infrastructure and Urbanization}

Spot 5 Supermode imagery (processed for $2.5 \mathrm{~m}$ resolution) has proven useful for urban planning in areas where sprawl is changing quickly due to rapid house construction and residential development, and where up-to-date information such as timely air photos are lacking. This is often the case in developing countries, and with a $60 \times$ $60 \mathrm{~km}$ swath, Duriex et al. [21] used object based image analysis and image segmentation to extract buildings, monitor and estimate urban sprawl in the entire Reunion Island, located in the Indian Ocean.

Another way to measure urbanization is via night lights, whereby Sutton [25] used DMSP-OLS ${ }^{2}$ and population data as a proxy measure for urban extent. More recently, Small et al. [17] used DMSP-OLS derived data to conclude that the brightness and coverage of stable night lights were correlated with human population density, built area density and economic activity at both the country and global scales [17]. "Night lights provide a means to quantify the size, number and spatial extent of human settlements worldwide" [17].

Landsat MSS, TM and ETM+ imagery was used to study urbanization rates in the Greater Dhaka area of Bangladesh in order to promote sustainable development [7]. The researchers found that as urbanization increased, water bodies shrank; cultivated land, wetlands and vegetation were all reduced. The government did not adequately respond to population growth, permitting settlers to establish themselves in wetlands and low-lying regions prone to flooding [7]. They also noted that land speculation attracted settlers and the subsequent conversion of arable land and natural areas. The authors pointed out that Landsat MSS imagery had a course spatial resolution (79 $\mathrm{m})$ that hampered classification accuracy, thus limiting its use $[7,95]$.

Other data used in this study included: municipal

${ }^{2}$ DMSP-OLS data was also used by Waluda et al., (2004) to detect night fishing efforts in the eastern Pacific. 
boundaries, road networks, elevation, geomorphic units, topography, demographic, slope and GDP. Important factors included economic development and industrialization, which contributed to rapid urbanization (rise of the ready-made garments industry), while topography affected its direction [7].

Ji et al. [23] formulated urban sprawl metrics that linked construction-based land consumption to remotely sensed land change data in metropolitan Kansas City. They found this method superior to using population data "because usually construction activities, as compared to population change, reflect directly economic opportunities as the major driving force of land alteration," [23]. Their dataset was composed of Landsat imagery (MSS, TM and ETM+), historical photos, and USGS topographic maps. Landscape metrics, such as patch density, largest patch density and the aggregation index of forested and nonforested vegetation were calculated using the FRAGSTATS ${ }^{3}$ program. The authors were able to identify slow and fast growing areas and concluded that larger spatial units such as metropolitan areas better reveal landscape effects of urbanization [23].

Bhatta et al. [19] note that defining urban sprawl and measuring it is a complicated process resulting in many variations. They define it as: "characterized by unplanned and uneven pattern of growth, driven by multitude of processes and leading to inefficient resource utilization" [19]. They also suggest using the entropy method to best integrate urban sprawl metrics with remote sensing and GIS. According to the authors "Shannon's entropy (Hn) can be used to measure the degree of spatial concentration or dispersion of a geographical variable (xi) among n zones" [19].

They also note that the imagery used should ideally have a fine enough spatial resolution to represent individual units such as parcels or houses. However, they point out that high-resolution imagery can result in the interpreter identifying high object diversity, which complicates classification algorithms [19]. Nevertheless, their article reviews several approaches to quantifying urban sprawl without applying the entropy method.

Meanwhile, Martinuzzi et al. [22] used Landsat ETM+ imagery, along with NOAA air photos and US Census data and urban-rural classifications to identify high and low urban density patterns in Puerto Rico. To assess accuracy, the authors used a random sample of ground control points for urban and non-urban categories evaluated against the air photos. Using this methodology they found that $11 \%$ of the island was covered by urban or built-up surfaces and that "Nearly half of the total development is occurring outside of the solid urban centers,

\footnotetext{
3"FRAGSTATS is a computer software program designed to compute a wide variety of landscape metrics for categorical map patterns" (UMASS Landscape Ecology Lab, 2011).
}

covering one-quarter of the best lands for agriculture, impacting watersheds and reducing urban spaces" [22]. When divided into three regions, the researchers found that $16 \%$ of the island was Urban, $36 \%$ was Sparsely Populated Rural and 48\% was Densely Populated Rural. They reiterated the need for the island to have an effective land use plan in a context where the population density rivals that of New Jersey [22].

In many places, such as in developing countries where municipal records, building permits, road construction and utility infrastructure locations are often not readily available or updated, remote sensing can provide "fundamental observations of urban growth and environmental conditions" [24]. These authors note the primacy for monitoring environmental conditions, more so than for urban planning, particularly where informal settlements are continually expanding. In their study they discuss the use of vegetation indices and temperature data from Landsat 7 imagery.

Lastly, Rajasekar and Weng [20] utilized MODIS and ASTER imagery to monitor the urban heat island in and around Indianapolis, Indiana. They used day and night land surface temperature (LST) MODIS images to create a continuous surface and concluded that they offer great potential to monitor the urban heat island phenomenon (whereby air temperatures in densely urbanized areas are higher than those in the countryside). However, heat islands were easier to distinguish in the summer months of June to August. When using ASTER data, the authors found that "areas with maximum heat signatures were found to have a strong correlation with impervious surfaces" [20].

Rhinane et al. [15] looked at urban ground temperature, building density and "cooler" areas. The latter, were vegetated zones, pointing to the importance of green spaces in controlling the heat island phenomenon.

\subsection{Archaeology and Remote Sensing}

Compared to what Siart et al., [97] call conventional archaeological GIS applications, the authors in this category propose a multi-method approach to geoarcheaological landscape reconstructions which involve RS, DEM analysis, GPS data, surveying, least-cost analysis, soils, predictive modeling and candidate site selection. Part of their approach involved identifying "aspects of landscape character which might have affected past activity or occupation choices," rather than directly locating archaeological sites or features [97]. One such tactic was to analyze the spatial distribution of Bronze Age transit roads, which would have influenced the location of settlements in the study area of Crete. Part of their methods involved pansharpening Quickbird MS imagery to $0.6 \mathrm{~m}$ resolution and then creating iron oxide ratios (band 3 by 1), as well as infrared ratios (band 4 by 3 ) 
[97].

The authors concluded that for the Bronze Age inhabitants slope and topography were important determinants for spatial mobility and still useful for predicting potential road networks and new sites [97]. Predicting archaeological site distribution with RS data go back about two decades. In one example Custer et al. [56] used Landsat MSS imagery to classify parts of central Delaware into land cover classes to help predict the location of prehistoric sites.

In another application for archaeology, Daniels et al., [55] tested the use of radar to detect buried subsurface reflectors to a depth of $20 \mathrm{~cm}$. The authors used a scaterometer (operating in the P-band at $441 \mathrm{MHz}, 68 \mathrm{~cm}$ ) mounted above a truck as well as on an airplane to conclude that it's possible to detect buried objects in sandy desert areas up to $4.4 \mathrm{~m}$ deep. The authors also highlight numerous potential applications for microwave/VHF radar. They include: tectonic and engineering studies, fluvial geomorphology, glacier covers, subsurface photogrammetry and cartography [55]. In fact NASA radar has been used to explore deep canyons located on the moon [50].

Other projects involving NASA remote sensing and archaeology date back to the 1960s, when black and white and infrared photography from Apollo 11's SO65 multiband experiment was used to identify human-made prehistoric linear features in Arizona [51]. Since the 1970s, infrared images were found to be useful to archaeology because "buried or obscure cultural features may absorb and radiate solar energy in amounts that differ from that of the surrounding soil matrix, thereby revealing the features on the imagery" [51]. Thermal data is also useful, since "heat transfer through the soil will be affected by the presence of buried objects" [53].

Another application of RS for archaeology includes ground-penetrating radar (GPR), which allows non-invasive site exploration to avoid disturbance during excavation of features in sites of interest [50]. Quarto et al. [54] used this technique to find karst caves that contained prehistoric remains in southern Italy, while Hoerle et al. [98] used it to assess the conservation conditions of prehistoric rock art in South Africa. There's even a journal dedicated to this topic aptly named Remote Sensing in Archaeology.

\subsection{The Ecological Footprint, or the Landscape Infrastructure Footprint}

Few researchers are studying the alterations created by oil and gas companies' infrastructure features on the landscape. These include Janks et al. [73] and Janks and Prelat [74] who studied vegetation health in and around oil fields, deforestation rates as related to oil and agricultural roads and tracked remediation attempts on aban- doned well sites using Landsat MSS and TM im- agery. Musinsky et al. [72] used Landsat TM, air photos and videography to examine the relationship between oil roads and deforestation in Guatemala.

For other researchers [68-71,99-102] a central goal is to determine "the exact size and extent of the ecological footprint of energy development" [103]. Some of this works applies landscape ecology metrics to quantify the landscape disturbances in oil and gas concessions. These metrics include road or infrastructure density; habitat fragmentation; edge-effect zones; core areas and number of rivers crossed [38,68-69,71,100,101,104-109].

Regarding the landscape infrastructure footprint (LIF) Baynard [70] examined oil concessions in Venezuela using Landsat TM and ETM+ imagery. Change detection was calculated using the NDVI, a commonly used method for identifying biomass, crop estimates and areas prone to drought $[8,110-112]$, as well as climate change, biodiversity and wildlife ecology [113]. It "is considered among the best known indices and widely used to study and map the plants" [15].

For the oil landscape study in Venezuela, the resulting vegetation change maps showing gains, losses or no change helped determine the contribution of LIF to vegetation change. By also including the size of core areas, agricultural land, as well as the number and location of infrastructure intersecting rivers, the concessions were ranked on their environmental performance. This type of performance can be linked to sustainability.

In another study of oil development in remote regions, Baynard et al. [68] examined the spatial relationship between infrastructure pattern related to oil exploration and production (E\&P) and parallel activities, surface disturbance and the type of access available in specific oil concessions in eastern Ecuador. This approach combined large-scale Landsat-derived LULC maps, smaller-scale government LULC maps, soils data, protected areas and colonization zones. The authors found that controlledaccess and no-access to oil concessions greatly reduced deforestation rates by keeping settlers from establishing households in these remote regions. Meanwhile, areas where public-access roads, fertile soils and colonization zones overlapped were most prone to deforestation [68].

\subsection{Ecosystem Goods and Services}

By assessing ecosystem goods and services, economic activity, natural assets and ecological functions can be linked [114]. Goods and services which we obtain from ecosystems include: "provisioning services, such as food and water; regulating services, such as regulation of floods, drought and disease; supporting services, such as soil formation and nutrient cycling; and cultural services, such as recreational, spiritual, and other nonmaterial benefits" [115]. 
The first step is to acknowledge that ecosystems have value, or natural capital. Then they have to be valued. This can be accomplished by "assessing the contribution of ecosystem services to sustainable scale, fair distribution, and efficient allocation" [115]. This method focuses on economic or utilitarian value; whereby "ecosystems are deemed valuable because they provide environmental goods and services to humans," note Abson and Termansen [116]. It does not focus on intrinsic value, whereby an object has a value for its own sake [116].

Yet once a valuation method has been reached, a main way to fund ecosystem management is to provide payments. Known as payments for ecosystem services (PES) [3], these economic incentives provide a way to manage ecosystems by paying local stakeholders not to cut down trees or convert natural landscapes to other uses such as agriculture or urbanization.

Reducing greenhouse gas emissions from deforestation and degradation, known as REDD, is one such approach, which draws on financial resources from developed countries to halt deforestation in forest-rich developing countries [4,5]. This approach is rather new and being implemented by organizations such as the German Development Bank, the Nature Conservancy and the World Bank, with the duel objectives of conserving and managing [117]. Because of its newness, REDD programs are characterized by uncertainty and incomplete information [4,5]; however, as mentioned earlier, advances in remote sensing are improving understanding of social and ecological systems functioning [5] which can range from intact native ecosystems to highly modified ones [6].

Given that monitoring REDD programs involves detecting LUCC over space and time, RS data and techniques are therefore prime tools to accomplish these objectives. Newer research points to the potential for LIDAR to be used for identifying the forest non-forest boundary, making it "an ideal tool for exact deforestation monitoring", a key requirement for REDD [118].

\section{Conclusions}

This paper has described some of the researches that utilize remote sensing to address problems relating to economics (improving efficiency in fishing, aquaculture, water quality); social and health conditions (malaria, earthquakes and typhoons); improved planning of development infrastructure (urban sprawl, the landscape infrastructure footprint); modeling change into the past and future (archaeology, REDD); and risk assessment (reservoirs, population growth). Clearly the type of work reviewed here overlaps more than one category (i.e., urban sprawl problems that can be economic, environmental and social). The topics to which these studies were assigned were based on commonalities within the research.

The paradigm shift, if we may call it that, is that organizations and corporations possessing environmental assets need to understand their roles as land managers and engage in better oversight of the land and people where their assets lie and their economic activities take place. This means paying attention to the triple bottom line of sustainable development: economic, environmental and social issues across all company operations. The way to approach this is to value ecosystem goods and services that are offered by the landscapes under their management - that is, valuing natural capital as one of society's most important assets [115].

A proposed method of implementation is via precision land management (PLM). This set of practices builds on methods used in precision agriculture to integrate layers of data used to promote variable management practices within a given agricultural field $[119,120]$. In this case, instead of better predicting crop yields, applying fertilizers and pesticides only in the right locations to increase production and efficiency, extractive industries and others operating in natural areas would efficiently manage the activities and infrastructure affecting habitats and people in and around their natural assets.

As Mathieu [43] observes: "Earth Observation (EO) satellites can play a key role in this endeavor, as they are uniquely placed to monitor the state of our environment, in a global and consistent manner, ensuring sufficient resolution to capture the footprint of man-made activities". Through this approach major actors would be in a better position to predict outcomes of the social, environmental and economic interaction that result in a successful operation. By incorporating socioeconomic data and stakeholder input with RS data in a GIS environment, these land managers could "see" what portions of a given real estate are being/might be altered or converted; the relationship to natural areas (for both conservation and remediation purposes); the location and activities of local villagers, indigenous groups and land managers; as well as actions from competing economic actors such as loggers, hunters, gold miners and local resource users.

\section{Future Research}

This paper has focused mostly on the application of passive remote sensing satellite imagery. Nevertheless, many applications have not been covered in efforts to provide a general overview - such as CBERS data (see [121]). Recent developments in the use of Radar and LIDAR should be further explored. Regarding radar, for example, Interferometric SAR (InSAR or If SAR) has been used to develop terrain elevation data and subsequent multiple data sets have been compared to monitor land deformation with centimeter precision [122].

If SAR applications can detect whether a vehicle has 
moved along a road, data fusion methods that combine Geo SAR data with AIS (automatic identification system) ship transponder signals, optical image data and in situ information can detect whether a ship is hiding something [123]. These secret activities could indicate illegal fishing or illegal oil discharging [123].

Other noteworthy developments are real-time in-flight processing, "which is especially important for rapid response, emergency management, and intelligence, surveillance and reconnaissance (ISR) applications" and the introduction of video into commercial airborne photogrammetry [124].

Nevertheless, throughout the papers examined here, Landsat imagery comprises key data sets due to their continuous global coverage and free availability. And now, the recent release of Landsat 8 in February 2013 [125] is a boon to EO researchers, since this satellite overcomes the challenges created by Landsat 7's malfunction in 2003 [126].

Key sources for developments and applications in remote sensing include: Imaging Notes

(http://www.imagingnotes.com); Advances in Remote Sensing (http://www.scirp.org/journal/ars/);

Remote Sensing of Environment

(http://www.journals.elsevier.com/remote-sensing-ofenvironment/); Remote Sensing

(http://www.mdpi.com/journal/remotesensing);

International Journal of Remote Sensing

(http://www.tandfonline.com/toc/tres20/current\#.UboKs5

Vpsb0); Applied Remote Sensing Journal

(http://www.asciencejournal.net/asj/index.php/ARS);

Journal of Applied Remote Sensing

(http://spie.org/x3636.xml); Remote Sensing Letters (http://www.tandfonline.com/action/showMostCitedArtic les?journalCode=trsl20\#.UcRc1ZVrXE4);

GIScience \& Remote Sensing

(http://www.tandfonline.com/action/showMostCitedArticles?journalCode=tgrs20\#.UcRdL-5VrXE4);

International Journal of Digital Earth

(http://www.tandfonline.com/action/showMostCitedArtic les?journalCode=tjde20\#.UcRdYpVrXE4);

ISPRS Journal of Photogrammetry and Remote Sensing (http://www.journals.elsevier.com/isprs-journal-of-photo grammetry-and-remote-sensing/); International Journal of Applied Earth Observation and Geoinformation (http://www.journals.elsevier.com/international-journalof-applied-earth-observation-and-geoinformation/); and Advances in Space Research

(http://www.sciencedirect.com/science/jounal/02731177).

\section{Acknowledgements}

This work was based on a white paper written for Chevron Corporation's Next Generation Remote Sensing Team. Any errors, omissions or oversights are solely those of the author.

\section{REFERENCES}

[1] Economist, "Seeing the World for the Trees: An International Deal on Deforestation Makes It Ever More Important to Measure Earth's Woodlands," 2010.

http://www.economist.com/node/17730208/print

[2] P. J. O'Farrell, J. S. Donaldson and M. T. Hoffman, "The Influence of Ecosystem Goods and Services on Livestock Management Practices on the Bokkeveld Plateau, South Africa," Agriculture Ecosystems and Environment, Vol. 122, No. 3, 2007, pp. 312-324. doi.org/10.1016/j.agee.2007.01.025

[3] J. Farley and R. Costanza, "Payments for Ecosystem Services: From local to Global," Ecological Economics, Vol. 69, No. 11, 2010, pp. 2060-2068. doi.org/10.1016/i.ecolecon.2010.06.010

[4] P. J. Kanowski, C. L. McDermott and B. W. Cashmore, "Implementing REDD+: Lessons from Analysis of Forest Governance," Environmental Science and Policy, Vol. 14, No. 2, 2011, pp. 111-117. doi.org.dax.lib.unf.edu/10.1016/j.envsci.2010.11.007

[5] F. Hajek, M. J. Ventresca, J. Scriven and A. Castro, "Regime Building for REDD+: Evidence Form a Cluster of Local Initiatives in South-Eastern Peru," Environmental Science and Policy, Vol. 14, No. 2, 2011, pp. 201-215. doi.org/10.1016/j.envsci.2010.12.007

[6] G. Yapp, J. Walker and R. Thackway, "Linking Vegetation Type and Condition to Ecosystem Goods and Services, Ecological Complexity, Vol. 7, No. 3, 2010, pp. 292-301. doi.org/10.1016/j.ecocom.2010.04.008

[7] A. M. Dewan and Y. Yamaguchi, "Land Use and Land Cover Change in Greater Dhaka, Bangladesh: Using Remote Sensing to Promote Sustainable Urbanization," Applied Geography, Vol. 29, No. 3, 2009, pp. 390-401. doi.org/10.1016/j.apgeog.2008.12.005

[8] J. Southworth, D. Munroe and H. Nagendra, "Land Cover Change and Landscape Fragmentation-Comparing the Utility of Continuous Discrete Analyses for a Western Honduras Region," Agriculture Ecosystems and Environment, Vol. 101, No. 2-3, 2004, pp. 185-205. http://dx.doi.org/10.1016/i.agee.2003.09.011

[9] P. Mondal, "Quantifying Surface Gradients with a 2-Band Enhanced Vegetation Index (EVI2)," Ecological Indicators, Vol. 11, No. 3, 2011, pp. 918-924. doi.org/10.1016/j.ecolind.2010.10.006

[10] J, Krishnaswamy, K. S. Bawa, K. N. Ganeshaiah and M. C. Kiran, "Quantifying and Mapping Biodiversity and Ecosystem Services: Utility of a Multi-Season NDVI Based Mahalanobis Distance Surrogate," Remote Sensing of Environment, Vol. 113, No. 4, 2009, pp. 857-867. doi.org/10.1016/j.rse.2008.12.011

[11] R. R. Rindfuss, B. Entwisle, S. J. Walsh, C. F. Mena, C. M. Erlien and C. L. Gray, "Frontier Land Use Change: Synthesis, Challenges, and Next Steps," Annals of the Association of American Geographers, Vol. 97, No. 4, 2007, pp. 739-754. 
doi.org/10.1111/j.1467-8306.2007.00580.x

[12] B. L. Tuner, E. F. Lambin and A. Reenberg, "The Emergence of Land Change Science for Global Environmental Change and Sustainability," PNAS, Vol. 104, No. 52, 2007, pp. 20666-20671. doi.org/10.1073/pnas.0704119104

[13] E. Keys and W. J. McConnell, "Global Change and the Intensification of Agriculture in the Tropics," Global Environmental Change, Vol. 15, No. 4, 2005, pp. 320-337. doi.org/10.1016/j.gloenvcha.2005.04.004

[14] A. Veldkamp and E. F. Lambin. "Predicting land-Use Change," Agriculture, Ecosystems and Environment, Vol. 85, No. 1-3, 2001, pp. 1-6. doi.org/10.1016/S0167-8809(01)00199-2

[15] H. Rhinane, A. Hilali, H. Bahi and A. Berrada, "Contribution of Landsat TM Data for the Detection of Urban Heat Islands Areas Case of Casablanca," Journal of Geographic Information System, Vol. 4, 2012, pp. 20-26. doi.org/10.4236/jgis.2012.41003

[16] H. Rhinane, A. Hilali, A. Berrada and M. Hakdaouli, "Detecting Slums from SPOT Data in Casablanca Morocco Using an Object Based Approach," Journal of Geographic Information System, Vol. 3, No. 3, 2011, pp. 217-224. doi.org/10.4236/jgis.2011.33018

[17] C. Small, C. D. Elvidge, D. Balk and M. Montgomery, "Spatial Scaling of Stable Night Lights," Remote Sensing of Environment, Vol. 115, No. 2, 2011, pp. 269-280. doi.org/10.1016/j.rse.2010.08.021

[18] K. Corbley, "Caribbean Island Maps On-and-Off-Shore Habitats: Balancing Growth with Preservation," Imaging Notes, Vol. 25, No. 3, 2010, pp. 20-21. http://imagingnotes.com/go/article_freeJ.php?mp_id=228

[19] B. Bhatta, S. Saraswati and D. Bandyopadhyay, "Urban Sprawl Measurement from Remote Sensing Data," Applied Geography, Vol. 30, 2010, pp. 731-740. doi.org/10.1016/j.apgeog.2010.02.002

[20] U. Rajasekar and Q. Weng, "Urban Heat Island Monitoring and Analysis Using a Non-Parametric Model: A Case Study of Indianapolis," ISPRS Journal of Photogrammetry and Remote Sensing, Vol. 64, No. 1, 2009, pp. 8696. doi.org/10.1016/i.isprsiprs.2008.05.002

[21] L. Duriex, E. Lagabrielle and A. Nelson, "A Method for Monitoring Building Construction in Urban Sprawl Areas Using Object-Based Analysis of Spot 5 Images and Existing GIS Data," Photogrammetry and Remote Sensing, Vol. 63, No. 4, 2008, pp. 399-408. doi.org/10.1016/j.isprsjprs.2008.01.005

[22] S. Martinuzzi, W. A. Gould and O. M. R. González, "Land Development, Land Use, and Urban Sprawl in Puerto Rico Integrating Remote Sensing and Population Census Data," Landscape and Urban Planning, Vol. 79, No. 3-4, 2007, pp. 288-297.

doi.org/10.1016/j.landurbplan.2006.02.014

[23] W. Ji, J. Ma, R. W. Twibell and K. Underhill, "Characterizing Urban Sprawl Using Multi-Stage Remote Sensing Images and Landscape Metrics," Computers, Environments and Urban Systems, Vol. 30, No. 6, 2006, pp. 861-879. doi.org/10.1016/j.compenvurbsys.2005.09.002
[24] R. B. Miller and C. Small, "Cities from Space: Potential Applications of Remote Sensing in Urban Environmental Research and Policy," Environmental Science and Policy, Vol. 6, No. 2, 2003, pp. 129-137. doi.org/10.1016/S1462-9011(03)00002-9

[25] P. C. Sutton, "A Scale-Adjusted Measure of "Urban Sprawl” Using Nighttime Satellite Imagery," Remote Sensing of Environment, Vol. 86, No. 3, 2003, pp. 353-369. doi.org/10.1016/S0034-4257(03)00078-6

[26] C. R. Zagaglia, J. A. Lorenzzetti and J. L. Stech, "Remote Sensing Data and Longline Catches of Yellowfin Tuna (Thunnus albacores) in the Equatorial Atlantic," Remote Sensing of Environment, Vol. 93, No. 1-2, 2004, pp. 267281. doi.org/10.1016/j.rse.2004.07.015

[27] C. M. Waluda, C. Yamashiro, C. D. Elvidge, V. R. Hobson and P. G. Rodhouse, "Quantifying Light-Fishing for Dosidicus gigas in the Eastern Pacific Using Satellite Remote Sensing," Remote Sensing of Environment, Vol. 91, No. 2, 2004, pp. 129-133. doi.org/10.1016/j.rse.2004.02.006

[28] A. M. P. Santos, "Fisheries Oceanography Using Satellite and Airborne Remote Sensing Methods: A Review," Fisheries Research, Vol. 49, No. 1, 2000, pp. 1-20. doi.org/10.1016/S0165-7836(00)00201-0

[29] K. Rajitha, C. K. Mukherjee and R. V. Chandran, “Applications of Remote Sensing and GIS for Sustainable Management of Shrimp Culture in India," Aquacultural Engineering, Vo. 36, No. 1, 2007, pp. 1-17. doi.org/10.1016/j.aquaeng.2006.05.003

[30] V. Lucier and H. Pederson, "Linking Morphometric Characterization of Rocky Reef with Fine Scale Lobster Movement," Photogrammetry and Remote Sensing, Vol. 63, No. 5, 2008, pp. 496-509.

doi.org/10.1016/j.isprsjprs.2008.01.003

[31] C. Feldman, "Background of SeaWiFS Project," http://oceancolor.gsfc.nasa.gov/SeaWiFS/BACKGROUN D/SEAWIFS_BACKGROUND.html

[32] M. A. Montes-Hugo, K. Carder, R. J. Foy, J. Cannizzaro, E. Brown and S. Pegau, "Estimating Phytoplankton Biomass in Coastal Waters of Alaska Using Airborne Remote Sensing," Remote Sensing of Environment, Vol. 98, No. 4, 2005, pp. 481-493. doi.org/10.1016/j.rse.2005.08.013

[33] A. Simon and P. Shanmugam, "An Algorithm for Classification of Algal Blooms Using MODIS-Aqua Data in Oceanic Waters around India," Advances in Remote Sensing, Vol. 1, No. 2, 2012, pp. 35-51. doi.org/10.4236/ars.2012.12004

[34] S. P. Tiwari and P. Shanmugam, "An Optical Model for the Remote-Sensing of Absorption Coefficients of Phytoplankton in Oceanic/Coastal Waters," Advances in Remote Sensing, Vol. 1, Session 17, 2012, pp. 633-637. doi:10.4236/ars.2012.12003

[35] H. Hanaizumi, M. Akiba, H. Yamano and T. Matsunaga, "A Pan-Sharpening Method for Satellite Image-Based Coral Reef Monitoring With Higher Accuracy," Proceedings of the 11th International Coral Reef Symposium, Ft. Lauderdale, 7-11 July 2008, pp. 626-630.

[36] E. Chuvieco, I. Aguado, M. Yebra, H. Nieto, J. Salas, M. 
P. Martín, et al., "Development of a Framework for Fire Risk Assessment Using Remote Sensing and Geographic Information System Technologies," Ecological Modelling, Vol. 221, No. 1, 2010, pp. 46-58.

doi:10.1016/j.ecolmodel.2008.11.017

[37] L. A. Arroyo, C. Pascual and J. A. Manzanera, "Fire Models and Methods to Map Fuel Types: The Role of Remote Sensing," Forest Ecology and Management, Vol. 256, No. 6, 2008, pp. 1239-1252. doi:10.1016/j.foreco.2008.06.048

[38] FAO, "Fire Management-Global Assessment: A Thematic Study Prepared in the Framework of the Global Forest Resources Assessment 2005," FAO Forestry Paper 151, FAO, Rome, 2006. http://www.fao.org/docrep/009/a0969e/a0969e00.HTM

[39] Ö. Ceyhun and A. Yalçin, "Remote Sensing of Water Depths in Shallow Waters via Artificial Neural Networks," Estuarine, Coastal and Shelf Science, Vol. 89, No. 1, 2010, pp. 89-96. doi:10.1016/j.ecss.2010.05.015

[40] N. Chang, Y. J. Yang, J. A. Goodrich and A. Daranpob, "Development of the Metropolitan Water Availability Index (MWAI) and Short-Term Assessment with MultiScale Remote Sensing Techniques," Journal of Environmental Management, Vol. 91, No. 6, 2010, pp. 1397-1413. doi:10.1016/j.jenvman.2010.02.024

[41] S. Chen, L. Fang, L. Zhang and W. Huang, "Remote Sensing of Turbidity in Seawater Intrusion Reaches of Pearl River Estuary-A Case Study in Modaomen Water Way, China," Estuarine, Coastal and Shelf Science, Vol. 82, No. 1, 2009, pp. 119-127. doi:10.1016/j.ecss.2009.01.003

[42] E. H. Alcântara, J. L. Stech, J. A. Lorenzzetti, M. P. Bonnet, X. Casamitjana, A. T. Assireu, et al., "Remote Sensing of Water Surface Temperature and Heat Flux over a Tropical Hydroelectric Reservoir," Remote Sensing of Environment, Vol. 114, No. 11, 2010, pp. 2651-2665. doi:10.1016/j.rse.2010.06.002

[43] P. P. Mathieu, "Sustainable Development Using Earth Observations: Accounting from Above Forestry, Hydropower and Mining," Imaging Notes, Vol. 25, No. 4, 2010, pp. 24-27.

[44] D. Tang, D. R. Kester, Z. Wang, J. Lian and H. Kawamura, "AVHRR Satellite Remote Sensing and Shipboard Measurements of the Thermal Plume from the Daya Bay, Nuclear Power Station, China," Remote Sensing of Environment, Vol. 84, No. 4, 2003, pp. 506-515. doi:10.1016/S0034-4257(02)00149-9

[45] F. Wang and Y. J. Xu, "Development and Application of a Remote Sensing-Based Salinity Prediction Model for a Large Estuarine Lake in the US Gulf of Mexico Coast," Journal of Hydrology, Vol. 360, No. 1-4, 2008, pp. 184194. doi:10.1016/j.jhydrol.2008.07.036

[46] X. Li and M. C. J. Damen, "Coastline Change Detection with Satellite Remote Sensing for Environmental Management for the Pearl River Estuary, China," Journal of Marine Systems, Vol. 82, 2010, pp. S54-S61.

[47] R. Vinuchandran and D. Ramakrishnan, "Detection of Fronts from Ocean Colour Monitor Images Using Entropic Technique: A Case Study of Meso- and Micro-
Scale Chlorophyll Mapping in Bay of Bengal, India," Advances in Remote Sensing, Vol. 2, 2013, pp. 71-76. doi:10.4236/ars.2013.22010

[48] S. D. Drobot, "Using Remote Sensing Data to Develop Seasonal Outlooks for Arctic Regional Sea-Ice Minimum Extent," Remote Sensing of Environment, Vol. 111, No. 2-3, 2007, pp. 136-147. doi:10.1016/j.rse.2007.03.024

[49] C. Gordon, "Tracking Glacial Activity in Norway with Photogrammetry Software," Imaging Notes, Vol. 22, No. 1, 2007, pp. 24-29. http://imagingnotes.com/go/article_free.php?mp_id $=90$

[50] C. Coleman and M. Quijada, "NASA Earth Scientists Advance Space Archaeology," NASA, 2010. http://www.nasa.gov/topics/earth/features/space-archaeol ogy.html

[51] M. J. Giardino, "A History of NASA Remote Sensing Contributions to Archeology," Journal of Archaeological Science, Vol. 38, No. 9, 2011, pp. 2003-2009.

[52] L. Liang-jun and W. Yan-bin, "Application of RemoteSensing-Image Fusion to the Monitoring of Mining Induced Subsidence," Journal of China University of Mining and Technology, Vol. 18, No. 4, 2008, pp. 531- 536. doi:10.1016/S1006-1266(08)60289-8

[53] A. Rowlands and A. Sarris, "Detection of Exposed and Subsurface Archaeological Remains Using Multi-Sensor Remote Sensing," Journal of Archaeological Science, Vol. 34, No. 5, 2007, pp. 795-803.

doi:10.1016/j.jas.2006.06.018

[54] R. Quarto, D. Schiavone and I. Diaferia, "Ground Penetrating Radar Survey of a Prehistoric Site in Southern Italy," Journal of Archaeological Science, Vol. 34, No. 12, 2007, pp. 2071-2080. doi:10.1016/j.jas.2007.02.024

[55] J. Daniels, D. G. Blumberg, L. D. Vulfson, A. L. Kotlyar, V. Freiliker, G. Ronen and J. Ben-Asher, "Microwave Remote Sensing of Physically Buried Objects in the Negev Desert: Implications for Environmental Research," Remote of Environment, Vol. 86, No. 2, 2003 pp. 243-256. doi:10.1016/S0034-4257(03)00111-1

[56] J. F. Custer, T. Eveleigh, V. Klemas and I. Wells, “Application of LANDSAT Data and Synoptic Remote Sensing to Predictive Models for Prehistoric Archaeological Sites: An Example from the Delaware Coastal Plain," American Antiquity, Vol. 51, No. 3, 1986, pp. 572-588. doi: $10.2307 / 281753$

[57] J. K. Crowley, B. E. Hubbard and J. C. Mars, "Analysis of Potential Debris Flow Source Areas on Mount Shasta, California, by Using Airborne and Satellite Remote Sensing Data," Remote Sensing of Environment, Vol. 87, No. 2-3, 2003, pp. 345-358. doi:10.1016/j.rse.2003.08.003

[58] GMES (Global Monitoring for Environment and Security), "How Satellites Track a Mass Killer," 2012. http://esamultimedia.esa.int/docs/EarthObservation/GME S_Brief_Malaria_Issue23_December2012.pdf

[59] A. N. Hassan, N. E. Nogoumy and H. A. Kassem, "Characterization of Landscape Features Associated with Mosquito Breeding in Urban Cairo Using Remote Sensing," The Egyptian Journal of Remote Sensing and Space Science, 2013, pp. 1-7, in Press. 
[60] B. G. Jacob, J. E. Funes, E. J. Muturi and R. J. Novak, "Using Imaging Technologies to Control Malaria," Imaging Notes, Vol. 22, No. 1, 2007, pp. 18-23. $\mathrm{http}$ ://imagingnotes.com/go/article_free.php?mp_id=91

[61] P. M. Masouka, D. M. Claborn, R. G. Andre, J. Nigro, S. W. Gordon, T. A. Klein and H.-C. Kim, "Use of IKONOS and Landsat for Malaria Control in the Republic of Korea," Remote Sensing of Environment, Vol. 88, No. 1-2, 2003, pp. 187-194. doi:10.1016/j.rse.2003.04.009

[62] T.-W. Chuang, G. M. Henebry, J. S. Kimball, D. L. VanRoekel-Patton, M. B. Hildreth and M. C. Wimberly, "Satellite Microwave Remote Sensing for Environmental Modeling of Mosquito Population Dynamics," Remote Sensing of Environment, Vol. 125, 2012, pp. 147-156. doi:10.1016/j.rse.2012.07.018

[63] J. Bevington, B. Adams and R. Eguchi, "GEO-CAN Debuts to Map Haiti Damage," Imaging Notes, Vol. 25. No. 2, 2010, pp. 26-30. http://imagingnotes.com/go/article.php?mp_id=208

[64] R. Ann, "The National System for Geospatial Intelligence: Enhancing the Value and Reach of GEOINT," Pathfinder, Vol. 9, No. 1, 2011, pp. 8-9. http://www.scribd.com/doc/127404947/1-NGA-Pathfinde r-Jan-Feb-2011?secret_password=2hpcs5ns0depbofzqk4f

[65] E. Batchelor, "Canada Responds to Haiti Earthquake," Pathfinder, Vol. 8, No. 6, 2010, p. 16. http://www.scribd.com/doc/127400218/6-2010-Nov-Dec? secret_password=1 zmpyovoizcw01tcll1x

[66] N. Cutsforth, "CRS Impact: Myanmar Cyclone Relief and Coral Reef Monitoring," Imaging Notes, Vol. 25, No. 3, 2010, pp. 15-16. http://imagingnotes.com/go/article_freeJ.php?mp_id=227

[67] J. Jones, "NGA Lights Way in Boston Harbor," Pathfinder, Vol. 9, No. 1, 2011, p. 17. http://www.scribd.com/doc/127404947/1-NGA-Pathfinde r-Jan-Feb-2011?secret_password=2hpcs5ns0depbofzqk4f

[68] C. W. Baynard, J. M. Ellis and H. Davis, "Roads, Petroleum and Accessibility: The Case of Eastern Ecuador," GeoJournal, 2012, pp. 1-16. http://link.springer.com/content/pdf/10.1007\%2Fs10708012-9459-5.pdf

[69] C. W. Baynard, "Evaluating Disturbance of E\&P Access Roads," ESRI News for Petroleum, 2012, pp. 6-7. http://www.esri.com/library/newsletters/petroleum-perspe ctives/petrol-spring-2012.pdf

[70] C. W. Baynard, "The Landscape Infrastructure Footprint of Oil Development: Venezuela's Heavy Oil Belt," Ecological Indicators, Vol. 11, No. 3, 2011, pp. 789-810. doi:10.1016/j.ecolind.2010.10.005

[71] C. W. Baynard, "Using Geospatial Technologies to Quantify Environmental Sustainability Performance," Petroleum GIS Perspectives, 2009-2010, pp. 4-5. http://www.esri.com/library/newsletters/petroleum-perspe ctives/petrol-winter-2009-2010.pdf

[72] J. N. Musinsky, C. C. S. Reining, A. B. Rosenfeld and J. B. Thomsen, "An Analysis of Human Settlement along the Xan Oil Road in Laguna del Tigre National Park, Guatemala," Society of Petroleum Engineers, 1998. doi:10.2118/46824-MS
[73] J. S. Janks, A. E. Prelat and J. D. Wieser, "Remote Sensing Technology Applications to Environmental Assessments in the Oriente Region of Ecuador," Second Thematic Conference on Remote Sensing for Marine and Coastal Environments, New Orleans, 31 Jan-2 Feb 1994, pp. 633-644.

[74] J. S. Janks and A. E. Prelat, "Environmental Impact Assessment Using Remote Sensing Technology: Methodology and Case Studies," Society of Petroleum Engineers, 1994. doi:10.2118/27121-MS

[75] S. Pontius and K. Boyer, "In Fields Afar, NGS Product May Be Warfighters' Only Friend," National Geospatial Intelligence Agency, Springfield, 2007.

[76] J. D. Krasnow, "Scene Visualization Advancements Great Boon to Partners," Pathfinder, Vol. 10, No. 3, 2012, p. 20. https://www1.nga.mil/MediaRoom/Press\%20Kit/Docume nts/Pathfinder\%20Magazines/2012/2012_May-Jun.pdf

[77] S. Marchant, "Toolkit Empowers Warfighters for NetCentric Warfare," National Geospatial Intelligence Agency, Springfield, 2007.

[78] S. Lavorel, M. D. Flannigan, E. F. Lambin and M. C. Scholes, "Vulnerability of Land Systems to Fire: Interactions among Humans, Climate, the Atmosphere, and Ecosystems," Mitigation and Adaptation Strategies for Global Change, Vol. 12, No. 1, 2007, pp. 33-53. doi:10.1007/s11027-006-9046-5

[79] B. W. Duncan, G. Shao and F. W. Adrian, "Delineating a Managed Fire Regime and Exploring Its Relationship to the Natural Fire Regime in East Central Florida, USA: A Remote Sensing and GIS Approach," Forest Ecology and Management, Vol. 258, No. 2, 2009, pp. 132-145. doi:10.1016/j.foreco.2009.03.053

[80] A. M. S. Smith, N. A. Drake, M. J. Wooster, A. T. Hudak, Z. A. Holden and C. J. Gibbons, "Production of Landsat ETM+ Reference Imagery of Burned Areas within Southern African Savannahs: Comparison of Methods and Application to MODIS, "International Journal of Remote Sensing, Vol. 28, No. 2, 2007, pp. 2753-2775. doi:10.1080/01431160600954704

[81] MODIS, “Thermal Anomalies/Fire,” 2010. http://modis-land.gsfc.nasa.gov/fire.html

[82] ESA, “ATSR,” 2011. http://earth.esa.int/ers/eeo4.80/

[83] GLCF, "Landsat Imagery," 2013. http://www.landcover.org/data/landsat/

[84] NASA, "The Enhanced Thematic Mapper Plus," 2013. http://landsat.gsfc.nasa.gov/about/etm.$+ h t m l$

[85] S. Voigt, A. Tetzlaff, J. Zhang, C. Künzer, B. Zhukov, G. Strunz, et al., "Integrating Satellite Remote Sensing Techniques for Detection and Analysis of Uncontrolled Coal Seam Fires in North China," International Journal of Coal Geology, Vol. 59, No. 1-2, 2004, pp. 121-136. doi:10.1016/i.coal.2003.12.013

[86] Aster, "The Aster Instrument," 2004. http://asterweb.jpl.nasa.gov/instrument.asp

[87] Digital Globe, "Basic Imagery," 2013. http://www.digitalglobe.com/node/1544\#overview

[88] A. Prakash, K. Schaefer, W. K. Witte, K. Collins, R. Gens and M. P. Goyette, "Remote Sensing: GIS Based 
Investigation of a Boreal Forest Coal Fire," International Journal of Coal Geology, Vol. 86, No. 1, 2011, pp. 79-86. doi:10.1016/j.coal.2010.12.001

[89] NOAA NSIS, "Advanced Very High Resolution Radiometer-AVHRR," 2013. http://noaasis.noaa.gov/NOAASIS/ml/avhrr.html

[90] NOAA OSO, "NOAA's Environmental Satellites: A History," 2013. http://www.oso.noaa.gov/history/index.htm

[91] ANTRIX, "Indian Remote Sensing Satellite Programme," 2006. http://www.pecad.fas.usda.gov/pdfs/2006/MUrthi_Indian _Remote_Sensing_SaPro-2006-TRIAL.pdf

[92] L. Yuan and L. Zhang, "Mapping Large-Scale Distribution of Submerged Aquatic Vegetation Coverage Using Remote Sensing," Ecological Informatics, Vol. 3, No. 3, 2008, pp. 245-251. doi:10.1016/j.ecoinf.2008.01.004

[93] A. Garzelli and F. Nencini, "Panchromatic Sharpening of Remote Sensing Images Using a Multiscale Kalman Filter," Pattern Recognition, Vol. 40, No. 12, 2007, pp. 3568-3577. doi:10.1016/j.patcog.2007.05.002

[94] USGS, "Earth Observing 1 (EO-1)," 2011. http://eo1.usgs.gov

[95] USGS, "Landsat: A Global Land-Imaging Project," 2010. http://pubs.usgs.gov/fs/2010/3026/pdf/FS2010-3026.pdf

[96] SPOT, "Spot Satellite Imagery: Accuracy and Coverage Combined," 2013.

http://www2.astrium-geo.com/files/pmedia/public/r233_9 _geo_0013_spot_en_low.pdf

[97] C. Siart, B. Eitel and D. Panagiotopoulos, "Investigation of Past Archaeological Landscapes Using Remote Sensing and GIS: A Multi-Method Case Study from Mount Ida, Crete," Journal of Archaeological Science, Vol. 35, No. 11, 2008, pp. 2918-2926. doi:10.1016/j.jas.2008.06.006

[98] S. Hoerle, F. Huneau, A. Salomon and A. Denis, "Using Ground-Penetrating Radar to Assess the Conservation Condition of Rock-Art Sites," Comptes Rendus Geoscience, Vol. 339, No. 8, 2007, pp. 536-544. doi:10.1016/j.jas.2008.06.006

[99] M. Wilbert, J. Thomson and N. W. Culver, "Analysis of Habitat Fragmentation from Oil and Gas Development and Its Impacts on Wildlife: A Framework for Public Land Management Planning," The Wilderness Society, Washington DC, 2008.

http://www.fws.gov/southwest/ES/Documents/Oil-Gas-Fr agmentation-Wilbert\%20et\%20al\%202008.pdf

[100] Wilderness Society, "Habitat Fragmentation from Roads: Travel Planning Methods to Safeguard Bureau of Land Management Lands," The Wilderness Society, Washington DC, 2006.

https://partners.tws.org/wildscience/Publications1/Habitat $\% 20$ Fragmentation $\% 20$ from $\% 20$ Roads.pdf

[101] J. L. Thomson, T. S. Schaub, N. W. Culver and P. C. Aengst, "Wildlife at a Crossroads: Energy Development in Western Wyoming-Effects of Roads on Habitat in the Upper Green River Valley," The Wilderness Society, Washington DC, 2005.

http://wilderness.org/sites/default/files/wildlife-at-crossro ads-report.pdf

[102] P. Morton, C. Weller and J. T. Thomson, "Energy and Western Wildlands: A GIS Analysis of Economically Recoverable Oil and Gas," The Wilderness Society, Washington DC, 2002.

[103] P. Morton, C. Weller, J. Thomson, M. Haefele and N. Culver, "Drilling in the Rocky Mountains: How Much and at What Cost?" The Wilderness Society, Washington DC, 2004.

[104] NOAA DMSP, "OLS-Operational Linescan System," 2011. http://www.ngdc.noaa.gov/dmsp/sensors/ols.html

[105] E. Ivits, M. Cherlet, W. Mehl and S. Sommer, "Estimating the Ecological Status and Change of Riparian Zones in Andalusia Assessed by Multi-Temporal AVHHR Datasets," Ecological Indicators, Vol. 9, No. 3, 2009, pp. 422-431. doi:10.1016/j.ecolind.2008.05.013

[106] R. R. Schneider, J. B. Stelfox, S. Boutin and S. Wasel, "Managing the Cumulative Impacts of Land Uses in the Western Canadian Sedimentary Basin: A Modeling Approach," Conservation Ecology, Vol. 7, No. 1, 2003, pp. 1-11. http://www.ecologyandsociety.org/vol7/iss1/art8/

[107] R. T. T. Forman, D. Sperling, J. A. Bissonnette, A. P. Clevenger, C. D. Cutshall, V. H. Dale, et al., "Road Ecology: Science and Solutions," Island Press, Washington DC, 2003.

[108] J. L. Stein, J. A. Stein and H. A. Nix, "Spatial Analysis of Anthropogenic River Disturbance at Regional and Continental Scales: Identifying the Wild Rivers of Australia," Landscape and Urban Planning, Vol. 60, No. 1, 2002, pp. 1-25. doi:10.1016/S0169-2046(02)00048-8

[109] S. J. Dyer, J. P. O'Neill, S. M. Wasel and S. Boutin, "Avoidance of Industrial Development by Woodland Caribou," The Journal of Wildlife Management, Vol. 65, No. 3, 2001, pp. 531-542. doi:10.2307/3803106

[110] R. T. T. Forman and R. D. Deblinger, "The Ecological Road-Effect Zone of a Massachusetts (U.S.A.) Suburban Highway," Conservation Biology, Vol. 14, No. 1, 2000, pp. 36-46. doi:10.1046/j.1523-1739.2000.99088.x

[111] J. R. Jensen, "Introductory Digital Image Processing: A Remote Sensing Perspective," 3rd Edition, Pearson Prentice Hall Inc., Upper Saddle River, 2007.

[112] C. C. Funk and M. E. Brown, "Intra-Seasonal NDVI Change Projections in Semi-Arid Africa," Remote Sensing of Environment, Vol. 101, No. 2, 2006, pp. 249-256. doi:10.1016/i.rse.2005.12.014

[113] S. Aronoff, "Remote Sensing for GIS Managers," ESRI Press, Redlands, 2005.

[114] J. N. Hird and G. J. McDermid, "Noise Reduction of NDVI Time Series an Empirical Comparison of Selected Techniques," Remote Sensing of Environment, Vol. 113, No. 1, 2009, pp. 248-258. doi:10.1016/j.rse.2008.09.003

[115] O. A. Somorin, I. J. Visseren-Hamakers, B. Arts, D. J. Sonwa and A. M. Tiani, "REDD+ Policy Strategy in Cameroon: Actors, Institutions and Governance," Environmental Science and Policy, 2013, In Press. doi:10.1016/j.envsci.2013.02.004

[116] S. Liu, R. Constanza, S. Farber and A. Troy, "Valuing 
Ecosystem Services: Theory, Practice, and the Need for Transdisciplinary Synthesis," Annals of the New York Academy of Sciences, Vol. 1185, 2010, pp. 54-78. doi:10.1111/j.1749-6632.2009.05167.x

[117]D. J. Abson and M. Termansen, "Valuing Ecosystem Services in Terms of Ecological Risks and Returns," Conservation Biology, Vol. 25, No. 2, 2011, pp. 250-258.

[118] B. Blom, T. Sunderland and D. Murdiyarso, "Getting REDD to Work Locally: Lessons Learned from Integrated Conservation and Development Projects," Environmental Science and Policy, Vol. 13, No. 2, 2010, pp. 164-172. doi:10.1016/j.envsci.2010.01.002

[119] B. Koch, "Status and Future of Laser Scanning, Synthetic Aperture Radar and Hyperspectral Remote Sensing Data for Forest Biomass Assessment," ISPRS Journal of Photogrammetry and Remote Sensing, Vol. 65, No. 6, 2010, pp. 581-590. doi:10.1016/j.isprsjprs.2010.09.001

[120] J. Sims, "Rapidly Serving Imagery for Precision AG and County and State Governments," Imaging Notes, Vol. 24, No. 1, 2009, pp. 30-31.

$\mathrm{http}: / /$ imagingnotes.com/go/article_free.php?mp_id=157

[121] S. K. Seelan, S. Laguette, G. M. Casady and G. A. Seiel- stad, "Remote Sensing Applications for Precision Agriculture: A Learning Community Approach," Remote Sensing of Environment, Vol. 88, No. 1-2, 2003, pp. 157169. doi:10.1016/i.rse.2003.04.007

[122] J. C. N. Epiphanio, "CBERS: Remote Sensing Cooperation between Brazil and China," Imaging Notes, Vol. 23, No. 2, 2008, pp. 16-19.

http://www.imagingnotes.com/go/article_free.php?mp_id $=134$

[123] M. Luccio, "Aerial Cameras: Focus Shifts to Productivity," Imaging Notes, Vol. 25, No. 4, 2010, pp. 49-54. http://www.imagingnotes.com/go/article_freeJ.php?mp_i $\mathrm{d}=243$

[124] M. Luccio, "Radar Gets it Done: Neither Clouds nor Gloom of Night Blind a Radar Satellite," Imaging Notes, Vol. 25, No. 2, 2010, pp. 33-38. http://www.imagingnotes.com/go/article.php?mp_id=209

[125] USGS, "Landsat 8 (LDCM) History,” 2013. http://landsat.usgs.gov/about_ldcm.php

[126] USGS, "SLC-Off Products: Background," 2013. http://landsat.usgs.gov/products_slcoffbackground.php 